\title{
Towards Better Understanding of Concrete Containing Recycled Concrete Aggregate
}

\author{
Hisham Qasrawi and Iqbal Marie \\ Civil Engineering, Faculty of Engineering, The Hashemite University, Zarqa 13115, Jordan \\ Correspondence should be addressed to Hisham Qasrawi; hisham_qasrawi@yahoo.com
}

Received 20 May 2013; Revised 27 August 2013; Accepted 27 August 2013

Academic Editor: Amit Bandyopadhyay

Copyright ( 2013 H. Qasrawi and I. Marie. This is an open access article distributed under the Creative Commons Attribution License, which permits unrestricted use, distribution, and reproduction in any medium, provided the original work is properly cited.

The effect of using recycled concrete aggregates (RCA) on the basic properties of normal concrete is studied. First, recycled aggregate properties have been determined and compared to those of normal aggregates. Except for absorption, there was not a significant difference between the two. Later, recycled aggregates were introduced in concrete mixes. In these mixes, natural coarse aggregate was partly or totally replaced by recycled aggregates. Results show that the use of recycled aggregates has an adverse effect on the workability and air content of fresh concrete. Depending on the water/cement ratio and on the percent of the normal aggregate replaced by RCA, the concrete strength is reduced by $5 \%$ to $25 \%$, while the tensile strength is reduced by $4 \%$ to $14 \%$. All results are compared with previous research. As new in this research, the paper introduces a simple formula for the prediction of the modulus of elasticity of RCA concrete. Furthermore, the paper shows the variation of the air content of RAC.

\section{Introduction}

The average world production of concrete in our rapid developing industrialized world is about 6 billion tons per year [1] which has an adverse impact on the environment. Since earth is the source of the aggregates (either natural or crushed), then obtaining these amounts would have an adverse effect on the environment. Furthermore, demolishing concrete structures and dumping the concrete rubbles would aggravate the problem. Therefore, recycling construction material plays an important role to preserve the natural resources and helps to promote sustainable development in the protection of natural resources; thus reduces the disposal of demolition waste from old concrete [2]. Hence, recycling concrete wastes becomes important in getting rid of the demolished concrete, which accumulates with time. For example, the amounts of demolished buildings in Europe amount to around 180 million tons per year [3].

Old concrete and masonry that have "reached the end of the road" can be recycled and used not only as aggregate for new concrete, but also for a number of other applications in construction [4]. For example, since 1982, the ASTM definition of coarse aggregate has included crushed hydraulic cement concrete, and the definition of manufactured sand includes crushed concrete fines [4]. Similarly, the U.S. Army Corps of Engineers and the Federal Highway Administration encourage the use of recycled concrete as aggregate in their specifications and guides [5]. Several references [3-12] have presented literature survey and research results in the field of the use of recycled aggregate, concrete, and masonry and their effect on maintaining the environment. Based on these references, the advantages of using recycled aggregate in concrete can be summarized as follows.

1.1. Environmental Considerations. SBM [12] provided brief environmental considerations regarding the use of concrete, quoted in their own words: "In this time of increasing attention to the environmental impact of construction and sustainable development, Portland cement concrete has much to offer: (1) it is resource efficient-minimizing depletion of our natural resources; (2) it is inert, making it an ideal medium in which to recycle waste or industrial byproducts; (3) it is energy efficient, it is superior to wood and steel; (4) it is durable, continuing to gain strength with time; and finally (5) it is recyclable, fresh concrete is used on an as-needed 
basis (whatever is left over can be reused or reclaimed as aggregate), and old hardened concrete can be recycled and used as aggregate in new concrete or as fill and pavement base material." Parekh and Modhera [13] considered the use of RCA in concrete as an appropriate and "green" solution to the anticipated increased world-wide construction activity.

1.2. Economic Factors. SBM [12] considered that recycling concrete is an attractive option for governmental agencies and contractors alike because most municipalities impose tight environmental controls over opening of new aggregate sources or new dumping areas. By time, the increase of the cost of starting new quarries is increased and will be farther away. Hence, the cost and transport distances of conventional aggregates could continue to increase as sources become scarcer. Since landfill space is limited and can be far away, especially in urban areas, the disposal of demolished rubbles becomes costly and dumping fees will most likely rise as construction debris increases and the number of accessible landfills decreases. Such situation was faced in Hong Kong, and recycling aggregate was an attractive solution [14].

1.3. Solving the Problem of Lack of Materials. According to Kawakami and Tokshige [15], utilization of concrete that uses recycled aggregates as a construction material is expected to contribute to solving the issue of lack of raw materials, and thus would allow the construction of infrastructures using a circulatory system for resources. Such situation was faced in Hong Kong, and recycling aggregate was an attractive solution [14].

1.4. Other Uses. While unprocessed RCA is useful to be applied as many types of general bulk fill, bank protection, subbasement, road construction, and embankments, processed RCA can be applied to new concrete including lean and structural grade concrete, soil-cement pavement bases, and bituminous concrete [9]. Moreover, it has been used to produce high strength concrete [10].

The use of RCA for the production of concrete involves breaking demolished concrete into materials with specified size and quality. These materials can then be combined to produce aggregate of a predetermined grading and hence can be used in concrete. Moreover, the steel reinforcement can be recycled and then can be used as structural concrete reinforcement reducing the effect on natural resources.

In this research the authors investigate the use of RCA in normal concrete mixes and study the possible effects on some of the concrete properties. Also, the research will try to arrive at some unique relationships that can be used in the prediction of the properties of RCA concrete. Hence tries to help in providing specifications that can be applied to RCA and RCA concrete. The research is a continuation of a previously conducted research on the use of RCA in concrete [16].

\section{Common Specifications}

Because of the widespread use of RCA in concrete, several agencies have adapted special standards and specifications covering the use of these materials in concrete. In 1994, RILEM [17] issued the "Specifications for concrete with Recycled aggregates." In these specifications, the RCA is classified into three main categories: (a) type I aggregates which originate primarily from masonry rubble, (b) type II aggregates which originate primarily from concrete rubble, and (c) type III aggregates which consist of a blend of recycled aggregates and natural aggregates. The specifications provided the required properties of these types and the provision for their use.

In 2002 the Works Bureau of Hong Kong [14] issued a special standard, WBCT 2/2002, on the use of RCA in concrete. According to this specification, (a) for lower grade applications (a target design strength below $20 \mathrm{MPa}$ ), concrete with $100 \%$ recycled coarse aggregate is allowed, (b) recycled fines are not allowed to be used in concrete, and (c) for higher grade applications (up to C35 concrete), it is allowed to use a maximum of $20 \%$ replacement of virgin coarse aggregates by recycled aggregates, and the concrete can be used for general concrete applications except in water retaining structures.

Japan issued three standards for recycled aggregate for concrete, JIS A 5021, JIS A 5022, and JIS A 5023, for classes $\mathrm{H}, \mathrm{M}$, and L, respectively [18]. These classes can be used as follows: (a) class $\mathrm{H}$ in which no limitations are put on the type and segment for concrete and structures with a nominal strength of $45 \mathrm{MPa}$ or less, (b) class $\mathrm{M}$ for concrete used for members that are not subjected to frost action, such as piles, underground beam, and concrete filled in steel tubes, and (c) class $\mathrm{L}$ which can be used for backfill, blinding, and leveling concretes.

In addition to specification and standards, some wellknown committees and organizations, such as ECCO [4], FHA [5], CCA [7], ACI 555R [8], PCA and [9] OSSGA [19], published previous experience and guidelines for the use of RCA in concrete.

\section{Materials}

The cement used in all mixes is ordinary Portland cement conforming to ASTM C 150-92 Type I specifications. Natural coarse aggregate is crushed limestone from local sources. Gradation of the normal aggregates was obtained using ASTM C136. Natural coarse aggregate used in the mixes was obtained by combining various aggregates of different singlesized aggregates in order to arrive at a grading accepted by ASTM and BS standards. The procedure described by Montgomery and Sturgiss [20] has been followed in the preparation of RCA as follows. first, RCA was obtained by crushing the previously tested samples in the laboratory into manageable lumps and then crushing these lumps in a Los Angeles abrasion machine. These particles were then washed, dried, and sieved using the standard sieves for course aggregates. Any material passing sieve $5 \mathrm{~mm}$ (ASTM \#4) was discarded. Later, the sieved particles were combined in order 
TABLE 1: Physical properties of aggregates.

\begin{tabular}{lccc}
\hline Property & $\begin{array}{c}\text { Coarse } \\
\text { aggregate }\end{array}$ & $\begin{array}{c}\text { Fine } \\
\text { aggregate }\end{array}$ & RCA \\
\hline Specific gravity (SSD) & $\begin{array}{c}2.57 \\
(\mathrm{~s}=0.041)\end{array}$ & $\begin{array}{c}2.59 \\
(\mathrm{~s}=0.037)\end{array}$ & $\begin{array}{c}2.28 \\
(\mathrm{~s}=0.057)\end{array}$ \\
Water absorption & 1.67 & 1.9 & 5.8 \\
& $(\mathrm{~s}=0.052)$ & $(\mathrm{s}=0.071)$ & $(\mathrm{s}=0.121)$ \\
Rodded bulk density & $1502 \mathrm{~kg} / \mathrm{m}^{3}$ & - & $1310 \mathrm{~kg} / \mathrm{m}^{3}$ \\
& $(\mathrm{~s}=11.2)$ & - & $(\mathrm{s}=14.3)$ \\
LA abrasion $(\%)$ & 25 & - & 31 \\
\hline
\end{tabular}

s: standard deviation.

to obtain a gradation similar to that of the natural aggregates. By this, the possible effect of the change of gradation on the properties of concrete is minimized. The graduation of both natural and RCA aggregates is within ASTM C33 and BS 882 for grading requirements for coarse aggregate of nominal maximum size $20 \mathrm{~mm}$ (ASTM 1.5") to $5 \mathrm{~mm}$ (ASTM number 4). Natural sand, known locally as desert sand, is used in all mixes. The fineness modulus of sand is 1.76 . The sand is not within the ASTM C 33-92 standard limits but it is within the limits of BS 882: 1992 standards and is classified as "M" (medium sand). Although this sand is relatively fine, it has good properties and is commonly used in concrete mixes.

The specific gravity and absorption of the aggregates were measured using ASTM C 127 and ASTM C 128. In each case, representative samples were taken and tested according to the corresponding ASTM standard. For natural aggregate, the average of three values was calculated. Because of the higher variability in RCA results, the average of six values (taken from different crushed lots) was calculated. The results are presented in Table 1 . The hardness of the aggregates was obtained using ASTM C 131. The Los Angeles abrasion values of both aggregates are shown in the table. The compacted density (dry-rodded unit weight) of the aggregates was obtained using ASTM C 29.

From Table 1, RCA aggregate has lower specific gravity and higher absorption. The reduction in the density and specific gravity and the increase in absorption are attributed to the attachment of cement paste in the recycled aggregate [3]. Since the absorption is highly increased, Tsujino et al. [21] showed that using an oil-type surface improving agent reduced water absorption of low- and middle-quality recycled aggregate resulting in an enhanced concrete performance.

The RCA aggregate conformed to RILEM 1994 Type II, JIS A 5021 (Type M) and WBCT 2/2002 Type 2.

\section{Experimental Program}

In order to study the effect of the use of RCA in concrete, several concrete mixes have been prepared and tested in the laboratory. The following steps summarize the program that has been followed.

(1) Conventional concrete mixes of water/cement ratio of $0.45,0.55$, and 0.65 were designed and tested in the laboratory. All mixes were prepared and adjusted
TABle 2: Mix proportions.

\begin{tabular}{|c|c|c|c|c|c|}
\hline $\begin{array}{l}\text { Replacement ratio } \\
\text { (by volume of CA) }\end{array}$ & $\begin{array}{l}\text { Cement } \\
\mathrm{Kg} / \mathrm{m}^{3}\end{array}$ & $\begin{array}{l}\text { Water } \\
\mathrm{Kg} / \mathrm{m}^{3}\end{array}$ & $\begin{array}{c}\text { Coarse } \\
\text { aggregate } \\
\mathrm{Kg} / \mathrm{m}^{3}\end{array}$ & $\begin{array}{c}\text { Fine } \\
\text { aggregate } \\
\mathrm{Kg} / \mathrm{m}^{3}\end{array}$ & $\begin{array}{c}\mathrm{RCA} \\
\mathrm{Kg} / \mathrm{m}^{3}\end{array}$ \\
\hline \multicolumn{6}{|c|}{$w / c=0.65$} \\
\hline 0 & 303 & 197 & 985 & 775 & 0 \\
\hline 25 & 303 & 197 & 740 & 775 & 218 \\
\hline 50 & 303 & 197 & 495 & 775 & 436 \\
\hline 75 & 303 & 197 & 245 & 775 & 654 \\
\hline 100 & 303 & 197 & 0 & 775 & 873 \\
\hline \multicolumn{6}{|c|}{$w / c=0.55$} \\
\hline 0 & 358 & 197 & 985 & 740 & 0 \\
\hline 25 & 358 & 197 & 740 & 740 & 218 \\
\hline 50 & 358 & 197 & 495 & 740 & 436 \\
\hline 75 & 358 & 197 & 245 & 740 & 654 \\
\hline 100 & 358 & 197 & 0 & 740 & 873 \\
\hline \multicolumn{6}{|c|}{$w / c=0.45$} \\
\hline 0 & 438 & 197 & 985 & 675 & 0 \\
\hline 25 & 438 & 197 & 740 & 675 & 218 \\
\hline 50 & 438 & 197 & 495 & 675 & 436 \\
\hline 75 & 438 & 197 & 245 & 675 & 654 \\
\hline 100 & 438 & 197 & 0 & 675 & 873 \\
\hline
\end{tabular}

to obtain concrete of medium workability (slump 8 to $12 \mathrm{~cm}$ ). Guidance of the ACI 211.1 was introduced in the preliminary design of these mixes. Then, the mixture proportions were practically adjusted in the laboratory.

In order to keep the free water, cement, and sand contents constant in all mixes, a percent of the volume of coarse aggregate was replaced by a predetermined percentage of RCA. By this, the assumption of the absolute unit volume described in ACI 211.1 will not be affected. The percentage of the coarse aggregate that was replaced by RCA was $25 \%, 50 \%, 75 \%$, and $100 \%$ by volume. Table 2 summarizes the mix proportions.

(2) All mixes were tested for workability using the slump test described in ASTM C 143.

(3) The air content was measured in all mixes using the pressure method described in ASTM C 231.

(4) Several cubes of $100 \mathrm{~mm}(\approx 4$ inch) side length were prepared and cured in the laboratory in a water bath under a temperature of $20^{\circ} \pm 2^{\circ} \mathrm{C}\left(75^{\circ} \pm 3^{\circ} \mathrm{F}\right)$ and then tested at the age of 28 days for compressive strength. The average of three values was recorded as the strength of concrete.

(5) Several standard prisms of $100 \times 100 \times 500 \mathrm{~mm}(\approx$ $4 \times 4 \times 20$ inch) were prepared and cured in the laboratory in a water bath under a temperature of $20^{\circ} \pm 2^{\circ}\left(75^{\circ} \pm 3^{\circ} \mathrm{F}\right)$ and then tested at the age of 28 days for flexural tensile strength. The average of three values was recorded as the tensile strength of concrete. 
(6) Concrete containing RCA mixes were prepared by replacing a predetermined amount of the coarse aggregate by RCA, while keeping all other variables constant. The ratio of RCA used was $25,50,75$, and 100 percent by volume of coarse aggregate.

(7) Concrete containing RCA cubes and prisms were prepared and tested as in steps 4-6.

\section{Experimental Results}

The measured properties of fresh concrete are shown in Figures 1 and 2. Figure 1 shows the relationship between the percentage of the coarse aggregate replaced by RCA and the percentage of the original slump for all mixes. The workability of concrete reduces by the increase in the RCA content. The reduction is more significant in the lower $w / c$ ratios. Figure 2 shows the results of the air content for the various types of mixes. Generally, the air content increased when RCA was introduced. It has been observed that up to $25 \%$ replacement, the increase in air content is marginal and close to the expected value of ACI 211.1 for maximum size of aggregate of $20 \mathrm{~mm}$ ( $1 \mathrm{inch})$. For the higher percentage replacements, the air content was 1.5 to 2 times the expected value.

The measured properties of hardened concrete are shown in Figures 3, 4, and 5. Figure 3 shows the percentage reduction in the 28-day compressive strength when normal aggregate is replaced by RCA. The use of the RCA resulted in reduction of the compressive strength. This reduction increases by the increase in the percentage of RCA in the mix. Similar results are shown by Limbachiya et al. [3]. Figure 4 shows the percentage reduction in the 28-day tensile strength when normal aggregate is replaced by recycled aggregate. The use of the RCA resulted in reduction of the tensile strength. This reduction increases by the increase in the amount of RCA replacing normal aggregate. Also higher strength concretes suffered more strength reduction. However, the percent reduction in tensile strength was less than the reduction in compressive strength. For example, the use of $100 \%$ replacement reduced the compressive strength of the mixes by $25 \%$ for $w / c$ ratio 0.45 , while in the case of tensile strength this value is $14 \%$. Figure 5 shows the relationship between the RCA percent replacement and the ratio of the modulus of elasticity of RCA to that of the natural aggregate concrete. It is clear from the results that the modulus of elasticity is reduced when recycled aggregates are incorporated.

\section{Discussion of Results}

6.1. Workability. The reduction in workability can be attributed to the increase in water demand which is difficult to predict $[11,22,23]$. Similar to the results in Figure 1, Chen et al. [24] found that the slump of recycled concrete is lower than that of normal concrete and that the tendency becomes more significant at low water/cement ratios. Furthermore, they observed that the workability of recycled concrete can be improved if the recycled aggregate is washed. Yong and Teo [2] solved the problem of reduction in workability by soaking aggregates in water and then using the aggregate in

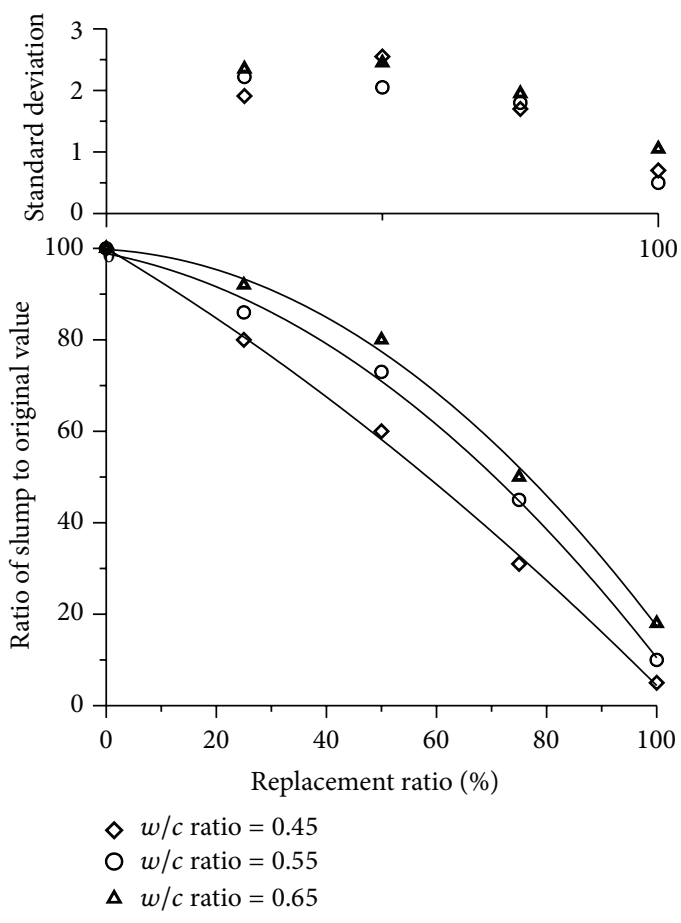

FIGURE 1: Relationship between the percentage of the coarse aggregate replaced by RCA and the percentage of the original slump.

saturated surface dry condition. Contrary to previous results, Limbachiya et al. [3] observed only a slight reduction in slump value with increasing RCA content in the mix, but this remained essentially within the accepted specified tolerances of $\pm 25 \mathrm{~mm}$ ( $1 \mathrm{inch})$.

6.2. Air Content. The increase in air content was attributed to the degree of cleanliness of RCA. According to Montgomery and Strugiss [20], increasing the level of cleanliness of RCA, in terms of the amount of mortar adhering to aggregate particles, has been found to reduce the air content and also to improve the workability, mass per unit volume, and compressive strength of concrete.

As well known, the increase in air content would lower the strength of concrete; therefore, the increase in air content might contribute, partly, to the loss in strength, especially for mixes containing more than $25 \%$ replacement.

6.3. Strength of Concrete. The compressive strength reduction can be attributed, mainly, to the replacement of normal aggregate by a lower quality aggregate. However, according to Limbachiya et al. and Corps of Engineers [25], approximately no change in strength is expected for replacement values below $30 \%$. From Figure 3, it can be also concluded that higher strength concretes suffered more reduction in strength. Chen et al. [24] found that at lower water/cement ratios, the compressive strength of recycled concrete is much lower than that of normal concrete but at higher water/cement ratios, the compressive strength of recycled concrete is similar to that of normal concrete. According to Park [11], this problem 


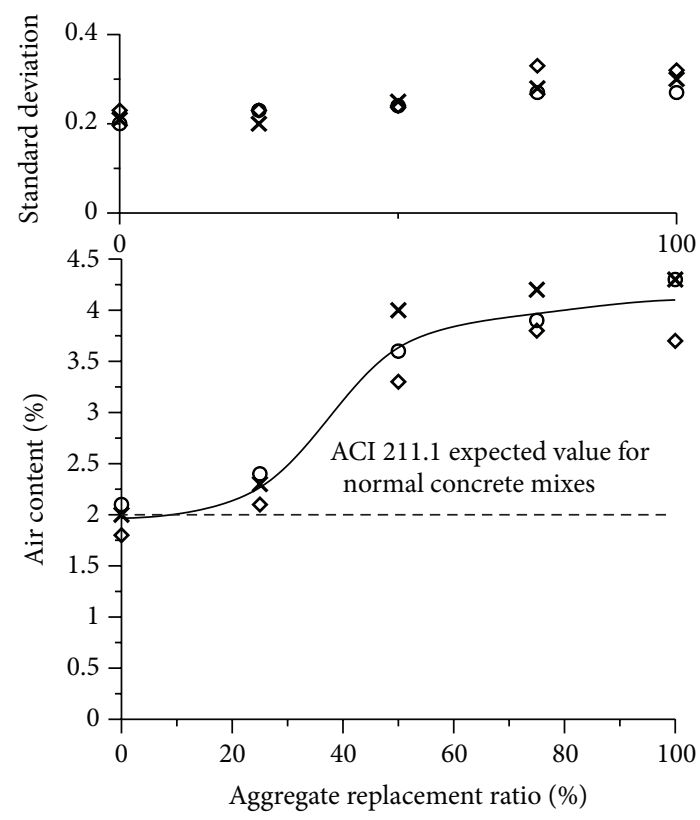

$\diamond w / c=0.45$

○ $w / c=0.55$

$\times \quad w / c=0.65$

- Average values

FIGURE 2: Relationship between the percentage of the coarse aggregate replaced by RCA and air content in fresh concrete.

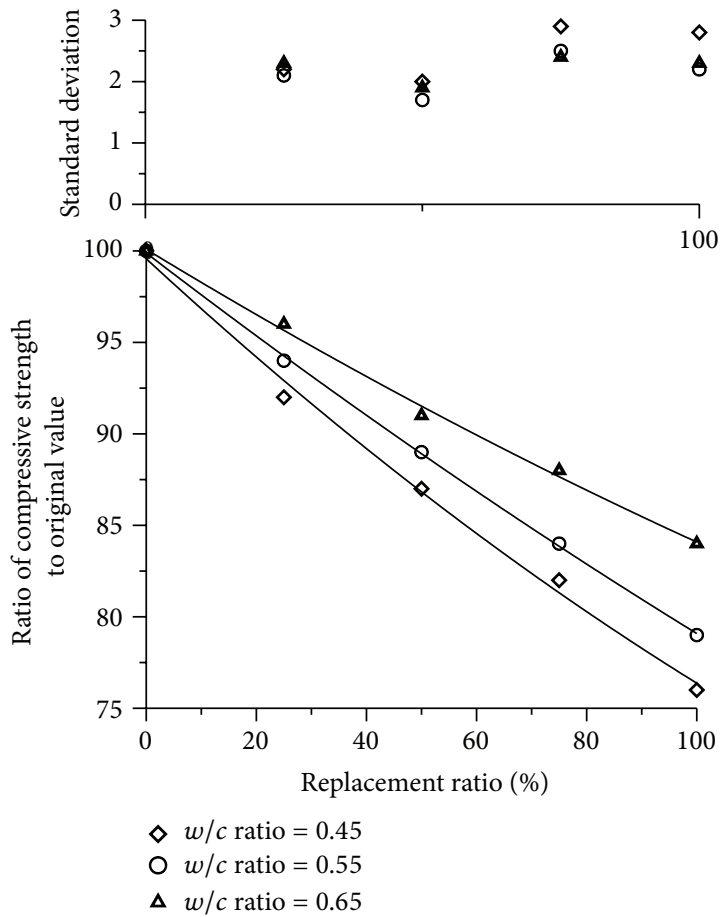

FIGURE 3: Relationship between the percentage of the coarse aggregate replaced by RCA and the reduction in the 28-day compressive strength.
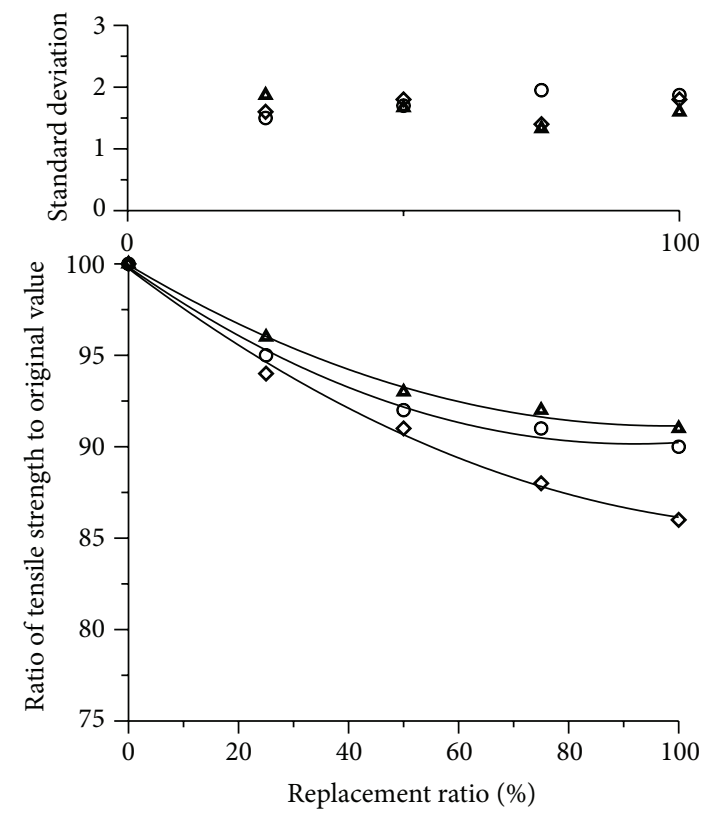

$\diamond w / c$ ratio $=0.45$

○ $w / c$ ratio $=0.55$

$\Delta w / c$ ratio $=0.65$

FIgURE 4: Relationship between the percentage of the coarse aggregate replaced by RCA and the reduction in the 28 -day tensile strength.

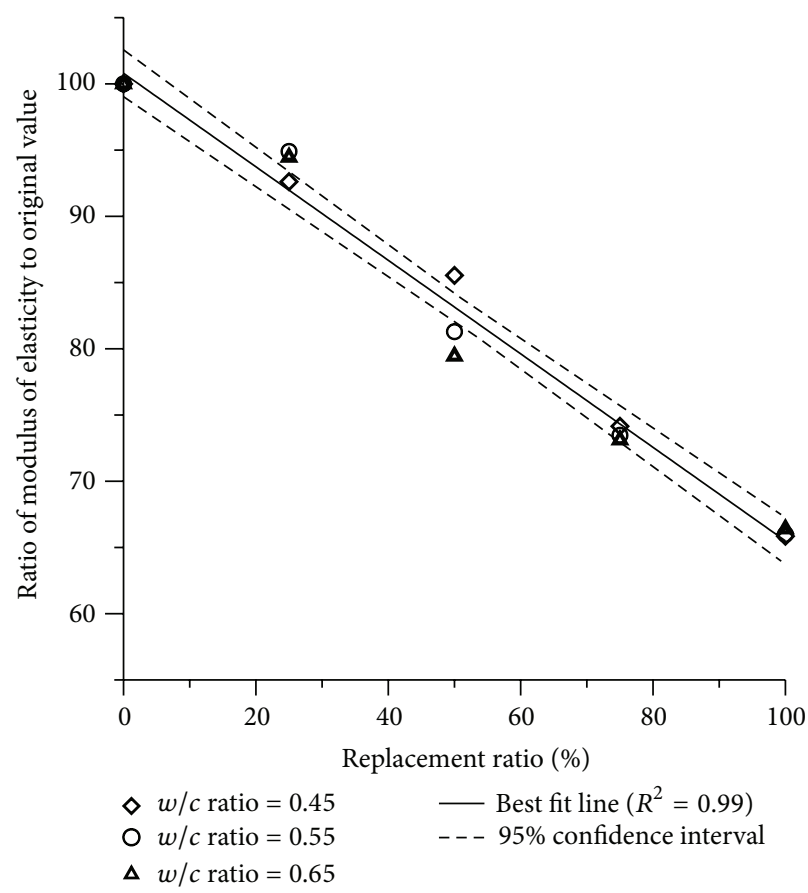

FIGURE 5: Relationship between the percentage of the coarse aggregate replaced by RCA and the ratio of the modulus of elasticity to zero-replacement. 
can be compensated for by adding extra cement. Unlike other results, at a replacement ratio of $25 \%$, Tia et al. [26] observed an increase in the 28-day compressive strength of the recycled aggregate concrete (5\% to $11 \%$ ) when compared to the control mix.

The loss in tensile strength has been observed by several researchers [11, 16, 24, 27]. Unlike compressive strength, this problem cannot be easily compensated for by adding extra cement [11]. On the contrary, Corps of Engineers [25] stated that no reduction in both compressive and tensile strengths is expected when recycled aggregate is used, especially if the ratio of the replacement is below 30\%. Also, Yong and Teo [2] reported that flexural tensile strength and the splitting tensile strength of both RCA and normal concrete are approximately equal.

Further analysis has been made in order to obtain the tensile/compressive ratio. The ratio of the tensile/compressive strength for all replacement ratios is shown in Figure 6. It is clear that the tensile/strength ratio increases by the increase in replacement ratio. Since high percentages are accompanied by lower strength, then the use of RCA can be advantageous if higher tensile/compressive ratio is required.

6.4. Modulus of Elasticity. The reduction in the modulus of elasticity is attributed to the reduction in the modulus of elasticity of the recycled aggregate [28-30]. In a comprehensive study on the use of recycled aggregate in concrete, Schoppe [28] found that 9 of the references he used in his study observed that the modulus of elasticity of concrete made with recycled aggregate is between $55 \%$ and $100 \%$ compared to that of normal concrete. Schoppe also observed a reduction between 0 and $20 \%$.

Although most authors reported that the reduction in modulus of elasticity increases by the increase in the replacement ratio, Chen et al. [24] observed a constant reduction in the modulus of elasticity (approximately about 25\%), irrespective of the replacement ratio. Moreover, Rahal [31] reported only a marginal $3 \%$ reduction in the modulus of elasticity for concretes of strength between 25 and $30 \mathrm{MPa}$.

From Figure 5 it is observed that a linear relationship exists between the replacement ratio and the reduction in the modulus of elasticity irrespective of the water/cement ratio. This finding is consistent with Chen et al. [24] that changing the water/cement ratio does not have a significant effect on the modulus of elasticity values.

Figure 7 was plotted in order to evaluate the possibility of applying international formulas for the relationship between compressive strength and modulus of elasticity. For comparison, the simplified ACI equation $\left[E=4.7 \sqrt{f_{c}^{\prime}}\right] \mathrm{GPa}$ and the BS 8110 equation $\left[E=9.1 \sqrt[3]{F_{c u}}\right]$ GPa are also plotted (in the ACI equation, the cylinder strength has been assumed to be 0.80 times the cube strength). From the figure, it is clear that neither the ACI 318 nor the BS 8110 equations can be applied for the prediction of the modulus of elasticity. It is also noted that all the modulus of elasticity values of the concrete containing recycled aggregate fall below the BS 8110 . This is not observed in the ACI 318 equation. Considering the BS 8110 equation as an upper bound, and using Figure 7, a simple

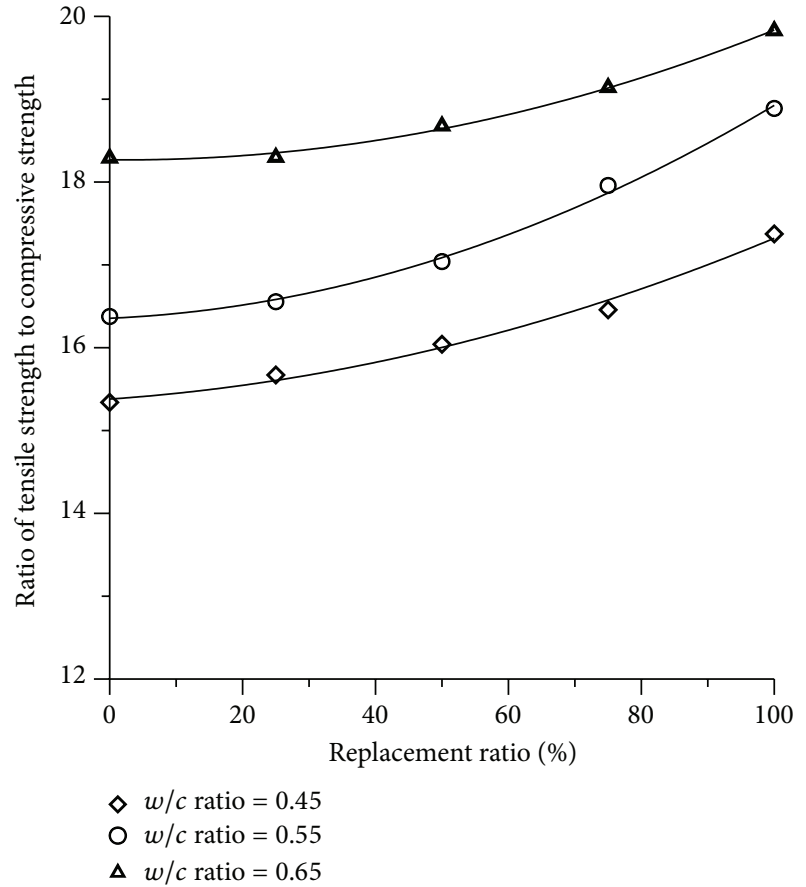

FIGURE 6: Relationship between the percentage of the coarse aggregate replaced by RCA and tensile/compressive strength at 28 days.

mathematical model to predict the modulus of elasticity in the form of

$$
E=F(1-C R)
$$

can be used to predict the modulus of elasticity $(E), R$ is the replacement ratio (\% of the volume of coarse aggregate), $F$ is a function of concrete strength $\left(F_{c u}\right)$, which represents an upper bound for the values (i.e., $E$ at $R=0$ ), and $C$ is a constant.

In the study, a simple equation to predict the modulus of elasticity, based on B.S. equation and (1), can be formulated:

$$
E=9.1 \sqrt[3]{F_{c u}}(1-0.353 R)
$$

where $E$ is the modulus of elasticity in $\mathrm{GPa}, F_{c u}$ is the cube strength in $\mathrm{MPa}$, and $R$ is the recycled aggregate to normal aggregate ratio.

In order to test the applicability of (1), the measured modulus of elasticity is plotted against the percent error in prediction when using (1), as shown in Figure 8. From the figure it is observed that the error in prediction ranges between $-10 \%$ and $+20 \%$. The error can be considered low (approximately within $\pm 10 \%)$ for the lower $w / c$ ratios $(0.55$ and 0.45 ). Also, it is observed that the lower the replacement ratio, the lower the error is. The $95 \%$ confidence interval is also shown in the plot. The average error for all data points is about $+6 \%$. Therefore, in this specific case, a better estimate can be obtained by multiplying the predicted value by 0.94 . 


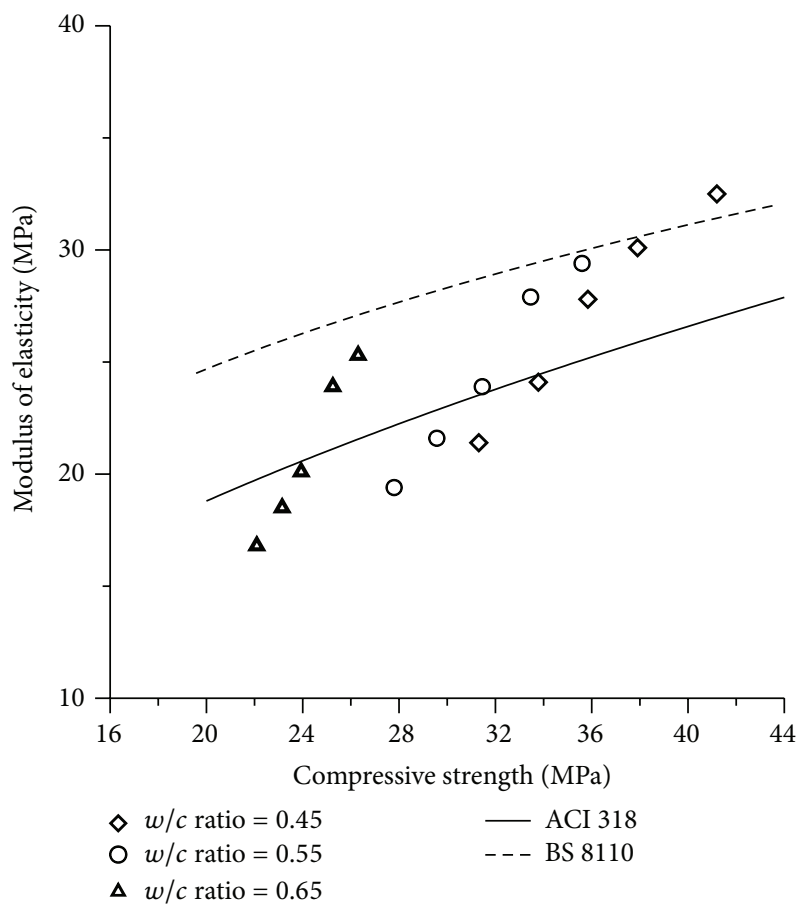

FIGURE 7: Relationship between the 28-day compressive strength and the modulus of elasticity.

\section{Conclusions}

Based on the study presented in this paper it can be concluded that the use of RCA as coarse aggregate is possible in normal concrete mixes. It is useful in reducing the environmental problems created by dumping these materials and also helps to maintain sustainability of the environment by reducing the new quarries needed for new concrete.

The use of RCA as coarse aggregate in concrete mixes has adversely affected the properties of fresh concrete. The workability of concrete is severely reduced. However, as it is well known, the use of plasticizers and superplasticizers will be beneficial in enhancing the workability. Regarding air content in fresh concrete, the use of RCA has an adverse effect on the air content in concrete especially for replacement ratios exceeding $25 \%$. On the other hand, approximately no effect is observed at replacements up to $25 \%$. Above this value, it has been observed that the air content is increased by a constant value, approximately $2 \%$, for replacements exceeding $50 \%$.

The use of RCA as coarse aggregate in concrete mixes has adversely affected the properties of hardened concrete. A decrease in compressive and tensile strengths has been observed. This decrease depends on the replacement ratio and the grade of concrete. For the same replacement ratio, the percentage reduction in compressive strength is more than that in tensile strength when RCA is incorporated. However, such problem can be easily coped for by reducing $w / c$ ratio which will result in increase in strength and hence can cope for such problem.

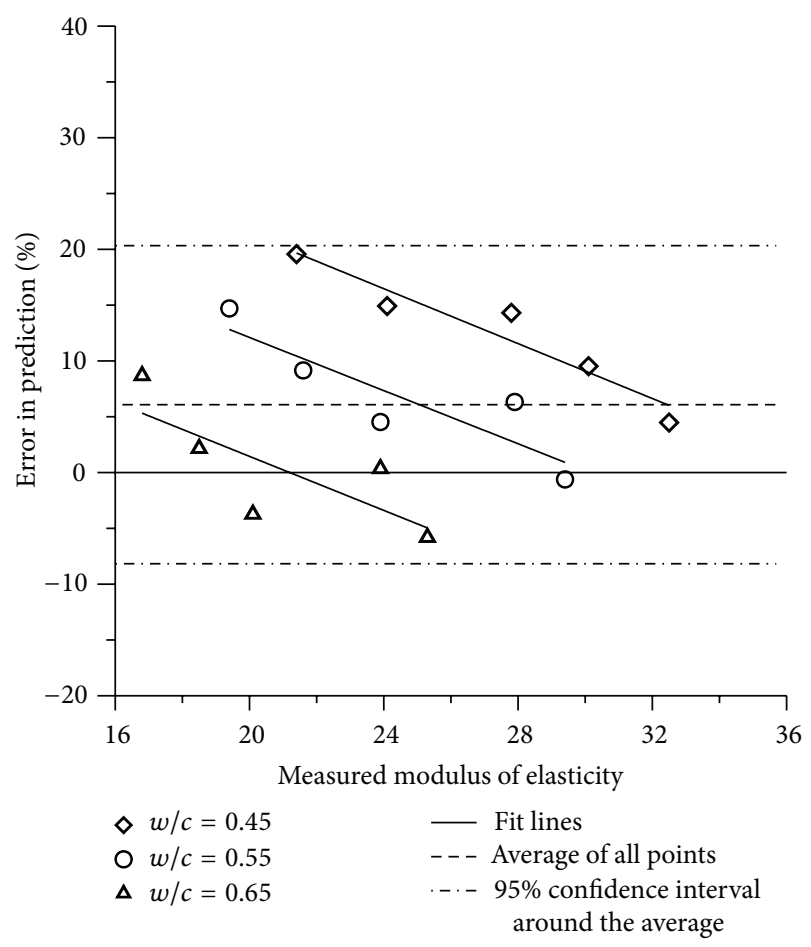

FIGURE 8: Relationship between the measured modulus of elasticity and percentage error in prediction using (2).

The modulus of elasticity of concrete has been reduced when RCA is incorporated irrespective of the $w / c$ ratio or the RCA replacement ratio. All values are below the BS 8110 equation. Also, both ACI 318 and BS 8110 equations for the prediction of the modulus of elasticity of concrete do not apply for concrete containing RCA. Therefore, an equation for predicting the modulus of elasticity of RCA concrete has been obtained. It is important to emphasize that this equation is applicable only for the conditions of this study. Hence, there is a need to find an adequate model to describe the modulus of elasticity for RCA concrete mixes before generalizing any formula. A model similar to the one in (1) is suggested.

At the end, it is important to note that because of the widespread use of RCA, it is important to provide specifications and standards that control the use of RCA in concrete. Each country can arrive at its own specification and standards. The Japanese and RILEM specifications can be bases for such issue.

\section{Further Research}

It is important to conduct further research concerning the use of RCA before applications. Properties such as shrinkage, durability, and fire endurance need to be extensively and carefully studied.

\section{References}

[1] S. Marinkovic and I. Ignjatovic, "Recycled aggregate concrete for structural use-an overview of technologies, properties and 
applications," in Proceedings of the ACES Workshop Innovative Materials and Techniques in Concrete Construction Corfu, October 2010.

[2] P. C. Yong and D. C. L. Teo, "Utilization of recycled aggregate as coarse aggregate in concrete," UNIMAS E-Journal of Civil Engineering, vol. 1, no. 1, pp. 1-6, 2009.

[3] M. Limbachiya, A. Koulouris, J. Roberts, and A. Fried, "Performance of recycled aggregate concrete," in Proceedings of the RILEM International Symposium on Environment-Conscious Materials and Systems for Sustainable Development, pp. 127-136, 2004.

[4] ECCO, Recycling Concrete and Masonry, Information Bulletin EV 22, Environmental Council of Concrete Organizations, Skokie, Ill, USA, 1999.

[5] FHA, Recycling Portland Cement Concrete, DP 47-85, Federal Highway Administration, Washington, DC, USA, 1985.

[6] K. Anderson, W. Uhlmeyer, and M. Russell, "Use of recycled concrete aggregate in PCCP," Literature Search WA-RD 726.1, State Department of Transportation, Washington, DC, USA, 2009.

[7] CCA Australia, Use of Recycled Aggregates in Construction, Cement Concrete \& Aggregates, New South Wales, Australia, 2008.

[8] A. C. I. Committee, "Removal and reuse of hardened concrete," Tech. Rep. ACI 555R-01, American Concrete Institute, Farmington Hills, Mich, USA.

[9] PCA, "Concrete technology—concrete design and production-materials: recycled aggregates," 2008, http://www.cement.org/tech/cct_aggregates_recycled.asp.

[10] Nelson and N. G. O. Shing Chai, High-Strength Structural Concrete with Recycled Aggregates [Ph.D. dissertation], University of Southern Queensland, 2004.

[11] S. G. Park, "Recycled concrete construction rubble as aggregate for new concrete," Study Report 86, BRANZ, 1999.

[12] S. B. M. Crusher and G. Mill, "Recycling concrete and masonry," 2010, http://www.miningequipments.net/knowledge/169.html.

[13] D. N. Parekh and C. D. Dr. Modhera, "Assessment I recycled aggregate concrete," Journal of Engineering Research and Studies, vol. 2, no. 1, pp. 1-9, 2011.

[14] W. Fong, J. Yeung, and C. Poon, "Hong Kong experience of using recycled aggregates from construction and demolition materials in ready mix concrete," in Proceedings of the International Workshop on Sustainable Development and Concrete Technology, pp. 267-275, Beijing, China, 2004.

[15] M. Kawakami and Tokushige, "Environmentally conscious concrete," in Proceedings of the Cement Based Materials \& Civil Infrastructure International Workshop (CBM-CI '07), pp. 155163, Karachi, Pakistan, 2007.

[16] H. Qasrawi, I. Marie, and H. Tantawi, "The use of concrete rubbles as course aggregate in concrete," in Proceedings of the 5th International Jordanian Civil Engineering Conference, pp. 281287, Jordan Engineers Association, Amman, Jordan, January 2012.

[17] RILEM, "Specifications for concrete with Recycled Aggregates," Materials and Structures, vol. 27, pp. 557-559, 1994.

[18] T. Noguchi, "Toward sustainable resource recycling in concrete society," in Proceedings of the 2nd International Conference on Sustainable Construction Materials and Technologies, pp. 321334, Alcona, Italy, June 2010.

[19] OSSGA, The ABCs of Recycled Aggregate, Ontario Stone, Sand and Gravel Association, 2010.
[20] D. G. Montgomery and D. Sturgiss, "Properties of concrete incorporating recycled concrete aggregates," in Proceedings of the National Symposium on the Use of Recycled Materials in Engineering Construction, pp. 153-156, Sydney, Australia, 1996.

[21] M. Tsujino, T. Noguchi, M. Tamura, M. Kanemats, I. Maruyama, and H. Nagai, "Study on the application of low-quality recycled coarse aggregate to concrete structure by surface modification treatment," in Proceedings of the 2nd Asian Concrete Federation Conference, pp. CMT36-CMT45, Bali, Indonesia, November 2006.

[22] A. D. Buck, "Recycled aggregate as a source of aggregate," ACI Journal, vol. 74, no. 5, pp. 212-219, 1977.

[23] T. C. Hansen and H. Narud, "Strength of recycled concrete made from crushed concrete coarse aggregate," Concrete International, vol. 5, no. 1, pp. 79-83, 1983.

[24] H.-J. Chen, T. Yen, and K.-H. Chen, "The use of building rubbles in concrete and mortar," Journal of the Chinese Institute of Engineers, vol. 26, no. 2, pp. 227-236, 2003.

[25] U.S. Army Corps of Engineers, "Reuse of concrete materials from building demolition," Tech. Rep. 200, 2004.

[26] M. Tia, N. Hossiney, and P. Bekoe, "Modulus of elasticity, creep and shrinkage of concrete-Phase III-part 2," Tech. Rep., Department of Civil and Coastal Engineering, University of Florida, Gainesville, Fla, USA.

[27] R. Kumutha and K. Vijai, "Strength of concrete incorporating aggregates recycled from demolition waste," Journal of Engineering and Applied Sciences, vol. 5, no. 5, pp. 64-71, 2010.

[28] B. Schoppe, Shrinkage \& Modulus of Elasticity in Concrete with Recycled Aggregates [M.S. thesis], Faculty of California, Polytechnic State University, 2011.

[29] J. Xiao, J. Li, and C. Zhang, "Mechanical properties of recycled aggregate concrete under uniaxial loading," Cement and Concrete Research, vol. 35, no. 6, pp. 1187-1194, 2005.

[30] M. C. Rao, S. K. Bhattacharyya, and S. V. Barai, "Influence of field recycled coarse aggregate on properties of concrete," Materials and Structures, vol. 44, no. 1, pp. 205-220, 2011.

[31] K. Rahal, "Mechanical properties of concrete with recycled coarse aggregate," Building and Environment, vol. 42, no. 1, pp. 407-415, 2007. 

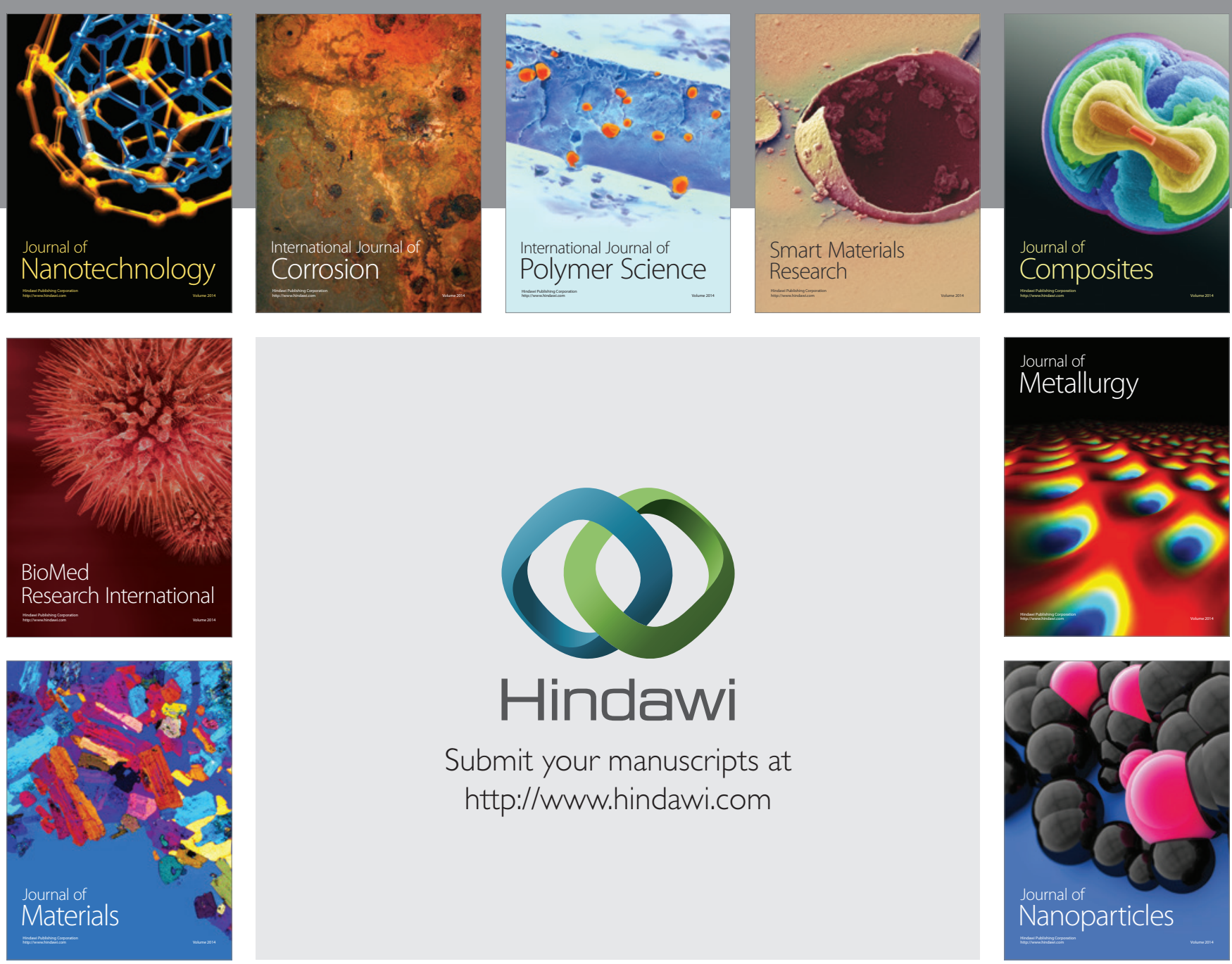

Submit your manuscripts at http://www.hindawi.com
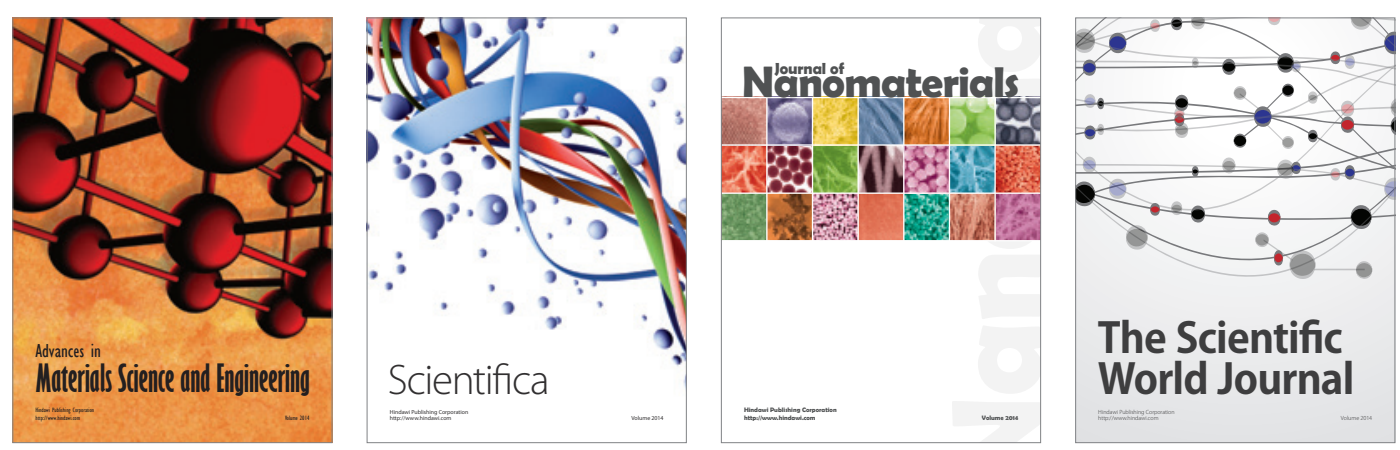

\section{The Scientific World Journal}
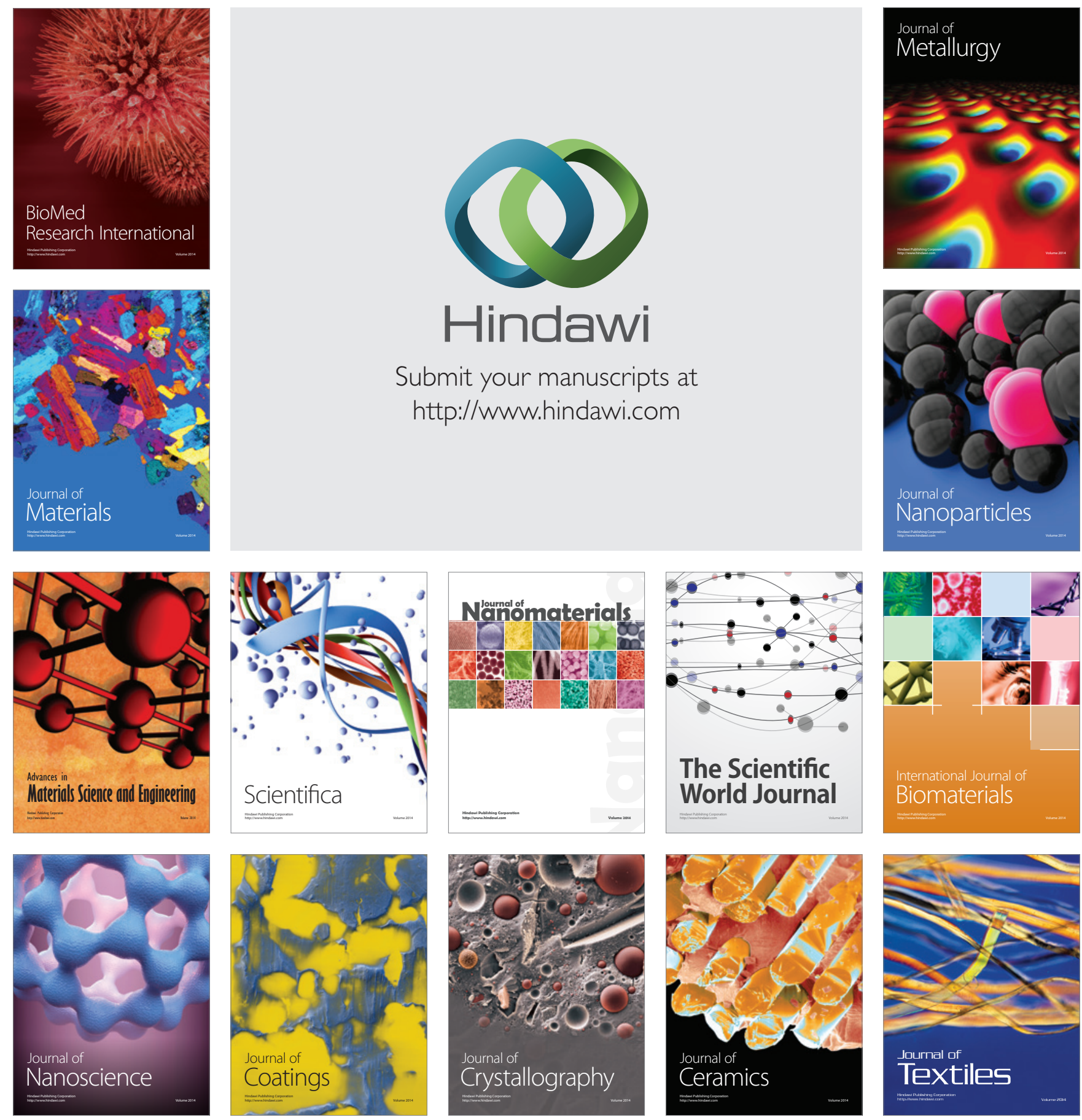